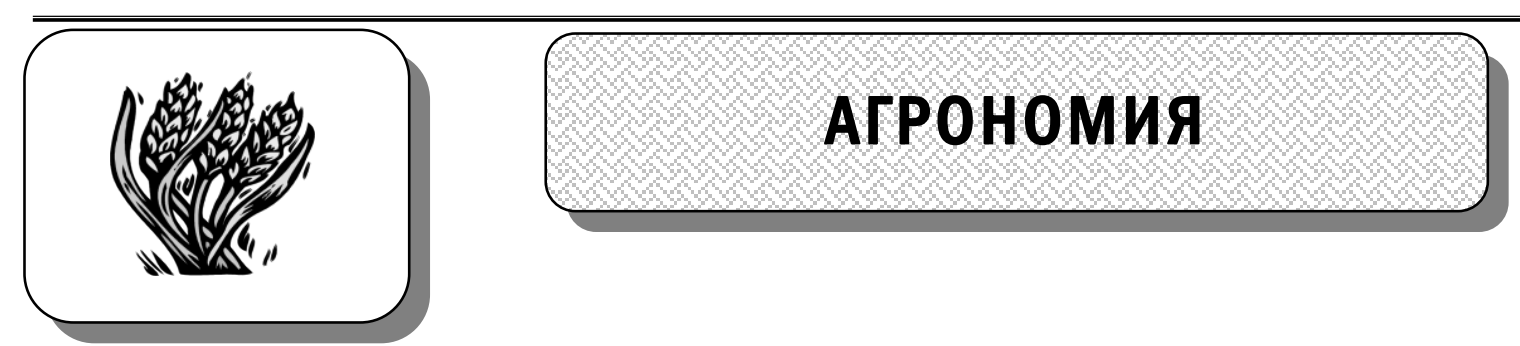

УдК 633.11:631.527

DOI: $10.36718 / 1819-4036-2020-5-3-9$

В. И. Ковтун, Л. Н. Ковтун

\title{
НОВЫЙ ВЫСОКОКАЧЕСТВЕННЫЙ ГЕНОТИП ПШЕНИЦЫ МЯГКОЙ ОЗИМОЙ ИСТОЧНИК, АДАПТИВНЫЙ К ВОЗДЕЛЫВАНИЮ В УСЛОВИЯХ ЮГА И ЮГО-ВОСТОКА РОССИИ
}

\author{
V. I. Kovtun, L. N. Kovtun \\ ISTOCHNIK, A NEW HIGH QUALITY SOFT WINTER WHEAT GENOTYPE, ADAPTIVE \\ TO CULTIVATION UNDER THE CONDITIONS OF THE SOUTH AND SOUTH-EAST OF RUSSIA
}

Ковтун Виктор Иванович - д-р с.-х. наук, зав. отделом селекции и первичного семеноводства озимых зерновых культур Северо-Кавказского федерального научного аграрного центра, Ставропольский край, Шпаковский р-н, г. Михайловск. E-mail: liudmila.kovtun@bk.ru

Ковтун Людмила Николаевна - канд. с.-х. наук, ст. науч. сотр. лаб. селекции и первичного семеноводства озимой пшеницы Северо-Кавказского федерального научного аграрного центра, Ставропольский край, Шпаковский р-н, г. Михайловск. E-mail: liudmila.kovtun@bk.ru

Цель исследования - создание нового сорта пшеницы мягкой озимой Источник, приспособленного к выращиванию по интенсивным и среднеинтенсивным технологиям в агроэкологических и почвенно-климатических условиях юга и юго-востока России. Основной метод создания сортов в Северо-Кавказском федеральном научном аграрном центре - внутривидовая, сложная, ступенчатая гибридизация, целенаправленный отбор. Для сокращения и повышения эфффективности селекционного процесса наряду с классической селекцией используется гаплоидная и маркерная. При гибридизации используются генетические источники, геномы которых содержат ярко выраженные маркеры основных хозяйственноценных признаков и свойств. Наблюдения, оценки, учет, определение качества зерна и
Kovtun Victor Ivanovich - Dr. Agr. Sci., Head, Department of Selection and Primary Seed Farming of Winter Grain Crops, North Caucasian Federal Scientific Agrarian Center, Stavropol Region, Shpakovsky District, Mikhaylovsk.

E-mail: liudmila.kovtun@bk.ru

Kovtun Lyudmila Nikolaevna - Cand. Agr. Sci., Senior Staff Scientist, Lab. Selection and Primary Seed Farming of Winter Grain Crops, North Caucasian Federal Scientific Agrarian Center, Stavropol Region, Shpakovsky District, Mikhaylovsk.

E-mail: liudmila .kovtun@bk.ru

хлеба, статистическая обработка результатов исследования выполнены согласно «Методике государственного сортоиспытания сельскохозяйственных культур» (1985), «Методике оценки технологических качеств зерна» (1971), «Методическим рекомендациям по оценке качества зерна», "Методике полевого опыта» (1985). Новый сорт пшеницы мягкой озимой Источник выделен из гибридной популящии от сложной внутривидовой гибридизации, где в качестве материнского растения использовался гибрид от скрещивания двух сортов (Донской сюрприз × Донской маяк), а в качестве отцовского - сорт Рапсодия. Вносились сложные минеральные удобрения в дозе $N_{40} P_{60} K_{40}$ килограммов на один гектар по действующему веществу. Проводилась предпосевная культивация на глубину 5-6 см. Пред- 
шественник - пар, норма высева - 500 всхожих

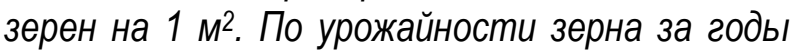
изучения (2017-2019) он превысил стандарт Гром на 1,17 m/2а. Это среднеспелый сорт. По качеству зерна Источник превышает стандартный сорт ченной пшеницы Гром. По основным показателям качества зерна и хлеба соответствует ГОСТу, который предъявляется к сильным пшеницам. Он устойчив к полеганию и болезням, обладает высокой засухоустойчивостью и зимоморозостойкостью. По этому показателю новый сорт достоверно превышает стандарт Гром, обладающий высокой морозостойкостью.

Ключевые слова: пшеница, сорт, генотип, качество, урожайность, морозостойкость.

The research objective was the creation of a new variety of soft winter wheat Istochnik adapted for the cultivation on intensive and mid-intensive technologies in agroecological and soil climatic conditions of the South and South-East of Russia. The main method of creation of the varieties in the North Caucasian Federal Scientific Agrarian Center is intraspecific, difficult, step hybridization, purposeful selection. For the reduction and increase of the efficiency of selection process, along with classical selection haploid and marker systems were used. At the hybridization genetic sources which genomes contained pronounced markers of the main economic and valuable signs and properties were used. Observation estimating, accounting, the quality of grain and bread assessment, statistical processing of the results of the research were made according to "The technique of the state variety testing of crops" (1985), "The technique of the assessment of technological qualities of grain" (1971), "Methodical recommendations about the assessment of grain quality", "Field experiment technique" (1985). A new variety of soft winter wheat 'Istochnik' was allocated from hybrid population from complicated intraspecific hybridization where as the maternal plant the hybrid from crossing of two varieties (Donskoy Surprise $\times$ Donskoy Mayak) and as fatherly the variety Rhapsody were used. Complex mineral fertilizers in the dose of $\mathrm{N}_{40} \mathrm{P}_{60} \mathrm{~K}_{40} \mathrm{~kg}$ on one hectare on active ingredient were introduced. Preceding cultivation on the depth of 5-6 cm was carried out. The predecessor was fallow; the norm of seeding was 500 germinating grains on $1 \mathrm{~m}^{2}$. On grain productivity for years of studying (2017-2019) it exceeded the standard Grom by 1.17 thectare. It is a mid-season variety. On grain quality Istochnik exceeds the standard variety of valuable wheat Grom. On the main indicators of the quality of grain and bread it corresponds to the state standard specification required of hard wheat. It is steady against drowning and diseases, possesses both high drought resistance and high frost resistance. On this indicator the new variety authentically exceeds the Grom standard possessing high frost resistance.

Keywords: wheat, variety, genotype, quality, productivity, frost resistance.

Введение. Хлеб - важнейший продукт питания не только населения России, но и практически всего земного шара. Высокое и устойчивое производство зерна пшеницы служит важным элементом политической и экономической стабильности государства, его продовольственной независимости и безопасности. Пшеничный колос - это символ достатка, успеха и счастья людей.

В России пшеница является ведущей продовольственной и стратегической культурой. В последние годы Россия занимает первое место в мире по экспорту зерна этой культуры. Ставропольский край - лидер по производству зерна пшеницы в Северо-Кавказском федеральном округе. Здесь пшеница высевается на площади более 2 млн гектаров. Выращенное зерно отличается высоким качеством и пользуется большим спросом на мировом рынке. Поставки зерна ставропольской пшеницы ежегодно на экспорт составляют до 5 млн т и более.

Учитывая особую важность этой культуры для нашей страны, следует постоянно увеличивать объемы производства зерна пшеницы и улучшать его качество. Решение данной задачи связано, прежде всего, с ускорением научно-технического прогресса, созданием и быстрым внедрением в производство новых высококонкурентных сортов в производство, постоянным совершенствованием технологии выращивания этих генотипов.

Для повышения эффективности производства и реализации зерна как на внутреннем, так и на мировом рынке важно создавать сорта с высокой продуктивностью и качеством. Создание таких сортов - довольно трудная и сложная задача, что связано с отрицательной корреляционной зависимостью между урожайностью и содержанием белка и клейковины в зерне. 
Тем не менее, некоторые селекционеры доказали возможность создания сортов, обладающих высокой урожайностью и высоким содержанием клейковины и белка в зерне [1-3].

Как отмечает М. М. Стрельникова, для формирования высокого урожая с повышенным процентом белка необходимы, прежде всего, достаточная обеспеченность растений азотом, повышенная температура воздуха и дефицит влаги в период созревания [4].

Цель исследования: создание нового сорта пшеницы мягкой озимой Источник, приспособленного к выращиванию по интенсивным и среднеинтенсивным технологиям в агроэкологических и почвенно-климатических и условиях юга и юго-востока России.

Материал и методика исследования. Главный метод синтеза новых генотипов пшеницы это внутривидовая сложная, ступенчатая гибридизация и непрерывный целенаправленный отбор. Вначале скрещиваются отдаленные в эколого-географическом отношении сортообразцы из коллекции Всероссийского института растениеводства, Украинского института растениеводства, СИММИТ и новые районированные сорта российской селекции. Затем полученные от таких скрещиваний генетические источники привлекаются в гибридизацию между собой или с инорайонными сортами с хорошо выраженными маркерами основных признаков.

С целью сокращения и повышения эффективности селекционного процесса наряду с классической селекцией используется гаплоидная и маркерная. При подборе родительских пар в качестве материнских и отцовских растений широко используем генетические источники, геномы которых содержат характерно выраженные маркеры основных признаков и свойств. На протяжении селекционного процесса ведется жесткий, непрерывный целенаправленный отбор модели генотипов универсального типа для условий юга и юго-востока России, разработанной в лаборатории селекции и первичного семеноводства озимой пшеницы.

Вносились сложные минеральные удобрения в дозе $\mathrm{N}_{40} \mathrm{P}_{60} \mathrm{~K}_{40}$ килограммов на один гектар по действующему веществу. Проводилась предпо- севная культивация на глубину 5-6 см. Предшественник - пар, норма высева - 500 всхожих зерен на 1 м². В годы исследования (2017-2019) посев проводили в оптимальные сроки или в конце оптимальных сроков сева, в зависимости от увлажнения почвы. Ранней весной, при достижении оптимальных температур воздуха (дневная температура превышала $+6{ }^{\circ} \mathrm{C}$, a среднесуточная $\left.+1{ }^{\circ} \mathrm{C}\right)$ подкармливали ослабленные зимовкой растения пшеницы аммиачной селитрой в дозе $\mathrm{N}_{30-40}$ кг на 1 гектар.

Наблюдения, оценки, учет, определение качества зерна и хлеба, статистическая обработка результатов исследований выполнены согласно следующим методическим указаниям: «Методика государственного сортоиспытания сельскохозяйственных культур» (1985) [5], «Методика оценки технологических качеств зерна» (1971) [6], «Методические рекомендации по оценке качества зерна» [7], «Методика полевого опыта» (1985) [8].

Результаты исследования. Новый сорт пшеницы мягкой озимой Источник создан в Северо-Кавказском федеральном научном аграрном центре. Получен он в результате непрерывного целенаправленного отбора из гибридной популяции от сложной внутривидовой гибридизации, где в качестве материнского растения использовался гибрид от скрещивания двух сортов зерноградской селекции (Донской сюрприз $\times$ Донской маяк), а в качестве отцовского сорт Рапсодия. Скрещивание родительских растений проведено в 2010 г., элитное растение выделено в F3 в 2013 г.

Новый высококачественный генотип Источник изучался в контрольном, предварительном и конкурсном испытании под селекционным номером (синоним) 2325/15. За высокое качество зерна и урожайность, устойчивость к болезням сорт Источник в 2019 г. был предложен для испытания и дальнейшего возделывания в Центрально-Черноземном, Нижне-Волжском и Северо-Кавказском регионах.

Результаты исследования (2017-2019 гг.) показывают, что новый сорт пшеницы Источник по урожайности зерна был достоверно выше стандарта Гром. Новый генотип превысил стандарт за эти годы на 1,17 т/га (табл. 1). 
Урожайность зерна и основные элементы, слагающие ее у нового сорта пшеницы Источник, КСИ (среднее 2017-2019 гг.)

\begin{tabular}{|l|c|c|c|c|}
\hline \multirow{2}{*}{\multicolumn{1}{|c|}{ Признак }} & \multicolumn{2}{|c|}{ Сорт } & \multirow{2}{*}{$\begin{array}{c}\text { × корту } \\
\text { Гром }\end{array}$} & \multirow{2}{*}{ НСР05 } \\
\cline { 2 - 3 } & Источник & Гром, st. & & \\
\hline Урожайность, т/га & 8,59 & 7,42 & $+1,17$ & 0,32 \\
\hline Длина колоса, см & 9,7 & 7,5 & $+2,2$ & 0,5 \\
\hline Число колосков в колосе, шт. & 18,6 & 16,3 & $+2,3$ & 1,4 \\
\hline Число зерен в колосе, шт. & 35,5 & 29,1 & $+6,4$ & 2,2 \\
\hline Масса зерна колоса, г & 1,6 & 1,2 & $+0,4$ & 0,1 \\
\hline Масса 1000 зерен, г & 50,7 & 38,7 & $+12,0$ & 3,1 \\
\hline
\end{tabular}

Колосья нового генотипа и стандартного сорта Гром различаются по длине и ширине. Длина колоса у сорта Источник в среднем за годы исследования составила 9,7 см, тогда как у стандарта Гром была всего 7,5 cм.

По числу колосков в колосе Источник в годы исследования достоверно превысил Гром, и это превышение у него составило 2,3 колоска на один колос. Изучаемый признак положительно влияет на продуктивность колоса.

Число зерен в колосе играет важную роль в увеличении урожайности зерна и широко используется селекционерами при создании высокопродуктивных сортов. Приведенные в таблице 1 сорта значительно различаются по числу зерен в колосе. В среднем за годы исследования новый генотип превысил стандарт на 6,4 зерна на один колос.

Масса зерна колоса играет важную роль в повышении урожайности. В среднем за годы исследования у нового сорта масса зерна колоса была равна 1,6 г, тогда как у стандарта 1,2 г. Это превышение было достоверным и значимым.

Macca 1000 зерен в значительной степени определяет качество семенного материала, его всхожесть и жизнеспособность, крупность и выполненность. В среднем за годы исследования сорт Источник по массе 1000 зерен превысил стандарт на 12,0 г.

Вегетационный период имеет большое значение и учитывается при подборе сортов для их возделывания в разных почвенно-климатических и агроэкологических условиях. Продолжительность вегетационного периода у нового сорта равна стандарту и составляет 251 день. По продолжительности вегетационного периода они относятся к группе среднеспелых сортов (табл. 2).

По высоте растений Источник является низкорослым сортом (87 см). По длине стебля в среднем за годы исследования новый сорт на 5 см выше стандартного полукарликового сорта Гром. Высота растений находится в зависимости от условий увлажнения в период роста стебля (VI-IX этапы органогенеза). В благоприятные годы она увеличивается, в засушливые уменьшается.

Годы изучения (2017-2019) показали, что всегда по высоте растений новый генотип был достоверно выше стандарта. Несомненно, условия вегетации влияют на формирование длины стебля у сортов озимой пшеницы, но все же решающее значение на изменчивость этого признака оказывает генетическая система сорта. Новый генотип, так же как и стандарт, обладает высокой устойчивостью к полеганию 5 баллов.

По числу продуктивных стеблей новый сорт достоверно превысил стандарт. Число продуктивных стеблей на $1 \mathrm{~m}^{2}$ у него составило 667 шт., у стандарта - 601 шт.

Для сорта Источник характерна высокая зимостойкость, которая составила 5 баллов, у стандарта она ниже - 4,9 балла. 


\section{Хозяйственно-биологическая характеристика генотипа пшеницы мягкой озимой Источник, КСИ (среднее 2017-2019 гг.)}

\begin{tabular}{|c|c|c|c|c|}
\hline \multirow{2}{*}{ Признак, свойство } & \multicolumn{2}{|c|}{ Сорт } & \multirow{2}{*}{$\begin{array}{c} \pm \text { к сорту } \\
\text { Гром }\end{array}$} & \multirow{2}{*}{$\mathrm{HCP}_{05}$} \\
\hline & Источник & Гром, st. & & \\
\hline Период вегетации, дни & 251 & 251 & 0 & 1,3 \\
\hline Длина стебля, см & 87 & 82 & +5 & 4,9 \\
\hline Устойчивость к полеганию, балл & 5,0 & 5,0 & 0 & 0,2 \\
\hline Продуктивная кустистость, шт. & 2,4 & 2,2 & $+0,2$ & 0 \\
\hline Число продуктивных стеблей на 1 м², шт. & 667 & 601 & +66 & 38 \\
\hline Зимостойкость, балл & 5,0 & 4,9 & $+0,1$ & 0,1 \\
\hline Морозостойкость, \% & 77,7 & 52,1 & $+25,6$ & 14,2 \\
\hline \multicolumn{5}{|l|}{ Поражаемость болезнями: } \\
\hline мучнистой росой, балл & 0 & $0-1$ & - & - \\
\hline пыльной головней, \% & 0 & 0 & - & - \\
\hline бурой ржавчиной, \% & 0 & $20-30$ & - & - \\
\hline желтой ржавчиной, \% & сл. & $5-10$ & - & - \\
\hline стеблевой ржавчиной, \% & сл. & $10-15$ & - & - \\
\hline вирусом желтой карликовости ячменя, \% & сл. & $15-20$ & - & - \\
\hline пиренофророзом, \% & сл. & $30-40$ & - & - \\
\hline септориозом колоса, \% & 0 & $35-40$ & - & - \\
\hline
\end{tabular}

Способность переносить низкие температуры у нового сорта значительно выше, чем у стандарта. В годы изучения морозостойкость у сортов пшеницы была разной. Это связано с условиями прохождения фаз закалки в осенний период, накопления сахаров в узлах кущения и снижения содержания свободной воды в листьях растений. У Источника она составила: в 2017 г. - 78,4 \%, в 2018 г. - 86,1 и в 2019 г. - 68,6 \%. У сорта Гром соответственно в эти годы она была 67,8; 49,5 и 39,8 \%. Из приведенных данных видно, что морозостойкость у нового генотипа была всегда выше, чем у стандарта. Условия среды значительно влияют на формирование морозостойкости у пшеницы, но важнейшая роль принадлежит генетической системе сорта, так как морозостойкость это генетически детерминированный признак. В среднем за три года (2017-2019) при промораживании сортов пшеницы при температурах минус

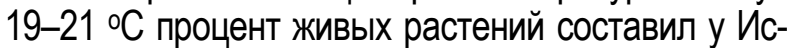
точника 77,7 ; у Грома - 52,1. Следует отметить, что стандартный сорт Гром отличается высокой морозостойкостью и районирован в Ростовской, Волгоградской и других областях России с суровыми климатическими условиями.

Новый сорт характеризуется высокой устойчивостью к основным болезням, поражающим пшеницу мягкую озимую в южных и юго-восточных регионах России. В годы исследования (2017-
2019) максимальное поражение болезнями в полевых условиях у нового генотипа составило: мучнистой росой - 0-1 балл; пыльной головней $0 \%$; бурой ржавчиной - $0 \%$; желтой ржавчиной следы; стеблевой ржавчиной - следы; вирусом желтой карликовости ячменя - следы; пиренофорозом - следы; септориозом колоса - 0 \%. Гром в средней и значительной степени поражался этими болезнями: мучнистой росой - 0-1 балл; пыльной головней - $0 \%$; бурой ржавчиной - 20-30; желтой ржавчиной - 5-10; стеблевой ржавчиной - 10-15; вирусом желтой карликовости ячменя - 15-20; пиренофорозом - 30-40; септориозом колоса $35-40 \%$.

По показателям качества зерна и хлеба сорт пшеницы Источник достоверно превзошел стандарт Гром (табл. 3). У сорта Источник они составили: натура - 819 г/л; стекловидность - $57 \%$; содержание белка в зерне - 15,7 \%; содержание клейковины в зерне - 30,3\%; группа клейковины первая; сила муки - 321 е. а.; объем хлеба из 100 г муки - 802 см³; общая оценка хлеба 4,8 балла. Уровень показателей качества зерна и хлеба за эти годы у стандарта Гром был следующий: натура - 806 г/л; стекловидность - 56 \%; содержание белка в зерне - 14,4\%; содержание клейковины в зерне - 26,8 \%; группа клейковины вторая; сила муки - 231 е. а., объем хлеба из 100 г муки - 763 см3; общая оценка хлеба - 4,1 балла. 
Биохимические, технологические и мукомольно-хлебопекарные показатели качества зерна у генотипа пшеницы мягкой озимой Источник, КСИ (среднее 2017-2019 гг.)

\begin{tabular}{|l|c|c|c|c|}
\hline \multirow{2}{*}{ Признак, свойство } & \multicolumn{2}{|c|}{ Сорт } & \multirow{2}{*}{ \pm к сорту Гром } & \multirow{2}{*}{ НСР 05} \\
\cline { 2 - 3 } & Источник & Гром, st. & & \\
\hline Натура зерна, г/л & 819 & 806 & +13 & 4,6 \\
\hline Стекловидность, \% & 57 & 56 & +1 & 3,7 \\
\hline Содержание, \% & & & & \\
\hline белка в зерне & 15,7 & 14,4 & $+1,3$ & 0,4 \\
\hline клейковины в зерне & 30,3 & 26,8 & $+3,5$ & 1,1 \\
\hline Качество клейковины, группа & I & II & - & - \\
\hline Сила муки, е.а. & 321 & 231 & +90 & 31 \\
\hline Объем хлеба, см ${ }^{3}$ & 802 & 763 & +39 & 21 \\
\hline Общая оценка хлеба, балл & 4,8 & 4,1 & $+0,7$ & 0,1 \\
\hline
\end{tabular}

Из вышеотмеченного следует, что новый сорт Источник по основным показателям качества зерна и хлеба соответствует ГОСТу, который предъявляется к сильным пшеницам. Необходимо отметить, что по качеству зерна и хлеба стандартный сорт пшеницы мягкой озимой Гром внесен в список ценных пшениц Российской Федерации, что и подтверждается полученными и приведенными в таблице 3 данными.

Заключение. Создан новый сорт пшеницы мягкой озимой Источник, который приспособлен к выращиванию по интенсивным и среднеинтенсивным технологиям в агроэкологических и почвенно-климатических и условиях юга и юговостока России.

Новый генотип прежде всего характеризуется высокой урожайностью и высоким качеством зерна и по этим признакам в годы исследования достоверно и значительно превышает стандартный сорт Гром. Кроме того, Источник отличается высокой устойчивостью к полеганию и высокой зимоморозостойкостью. По вегетационному периоду - среднеспелый, с высокой устойчивостью к патогенам: к бурой, желтой и стеблевой ржавчинам, мучнистой росе, пыльной головне, вирусу желтой карликовости ячменя, септориозу колоса и пиренофорозу. Источник устойчив к прорастанию и осыпанию зерна на корню.

\section{Литература}

1. Лыфренко С.Ф. Некоторые особенности генетического контроля признака содержания белка в зерне озимой мягкой пшеницы и возможности улучшения технологических качеств в процессе селекции // Селекция пшеницы на юге Украины. Одесса, 1980. C. $75-80$.

2. Ковтун В.И. Селекция высокоадаптивных сортов озимой мягкой пшеницы и нетрадиционные элементы технологии их возделывания в засушливых условиях юга России: Ростов н/Д.: Книга, 2002. 318 с.

3. Ковтун В.И., Ковтун Л.Н. Новый сорт универсального типа пшеницы мягкой озимой Батя, высоко адаптивный к возделыванию в разных почвенно-климатических условиях // Известия Оренбургского ГАУ. 2019. № 4 (78). C. 58-61.

4. Стрельникова М.М. Повышение качества зерна пшеницы. Киев: Урожай, 1971. С. 22-32.

5. Методика Государственного сортоиспытания сельскохозяйственных культур. М., 1985. $270 \mathrm{c}$.

6. Методика оценки технологических качеств зерна. М., 1971. 135 c.

7. Методические рекомендации по оценке качества зерна. М.: ВАСХНИЛ, 1977. 172 с.

8. Доспехов Б.А. Методика полевого опыта (с основами статистической обработки результатов исследований). М.: Агропромиздат, 1985. $351 \mathrm{c}$. 


\section{Literatura}

1. Lyfenko S.F. Nekotorye osobennosti geneticheskogo kontrolja priznaka soderzhanija belka $v$ zerne ozimoj mjagkoj pshenicy i vozmozhnosti uluchshenija tehnolo-gicheskih kachestv $v$ processe selekcii // Selekcija pshenicy na juge Ukrainy. Odessa, 1980. S. 75-80.

2. Kovtun V.I. Selekcija vysokoadaptivnyh sortov ozimoj mjagkoj pshenicy i netradicionnye jelementy tehnologii ih vozdelyvanija $v$ zasushlivyh uslovijah juga Rossii. Rostov n/D.: Kniga, 2002. $318 \mathrm{~s}$.

3. Kovtun V.I., Kovtun L.N. Novyj sort universal'nogo tipa pshenicy mjagkoj ozimoj Batja, vysoko adaptivnyj $\mathrm{k}$ vozdelyvaniju $\mathrm{v}$ raznyh pochvenno- klimaticheskih uslovijah // Izvestija Orenburgskogo GAU. 2019. № 4 (78). S. 58-61.

4. Strel'nikova M.M. Povyshenie kachestva zerna pshenicy. Kiev: Urozhaj, 1971. S. 22-32.

5. Metodika Gosudarstvennogo sortoispytanija sel'skohozjajstvennyh kul'tur. M., 1985. 270 s.

6. Metodika ocenki tehnologicheskih kachestv zerna. M., 1971. $135 \mathrm{~s}$.

7. Metodicheskie rekomendacii po ocenke kachestva zerna. M.: VASHNIL, 1977. $172 \mathrm{~s}$.

8. Dospehov B.A. Metodika polevogo opyta (s osnovami statisticheskoj obrabotki rezul'tatov issledovanij). M.: Agropromizdat, 1985. $351 \mathrm{~s}$. 